\title{
Interstitial Lung Disease: Seasonality of Hospitalizations and In-Hospital Mortality 2005-2015
}

\author{
Daniel von der Beck ${ }^{a}$ Friedrich Grimminger ${ }^{a} b \quad$ Werner Seeger $^{a}$ \\ Andreas Günther ${ }^{a, c}$ Benjamin Löh ${ }^{a, b}$ \\ aUniversities of Giessen and Marburg Lung Center (UGMLC), Member of the German Center for Lung Research \\ (DZL), Giessen, Germany; 'bepartment of Pulmonology, Hochtaunus Clinic, Bad Homburg, Germany; ' ${ }^{\mathrm{C}}$ Agaplesion \\ Lung Clinic Waldhof Elgershausen, Greifensstein, Germany
}

\section{Keywords}

Pulmonary fibrosis · Interstitial lung disease $\cdot$ Seasonality . Hospitalizations · Idiopathic pulmonary fibrosis

\begin{abstract}
Background: The overall incidence of interstitial lung disease and disease-associated mortality have been found on the rise. Hospitalizations for interstitial lung disease are typically caused by airway infection or the acute exacerbation of the underlying disease. Seasonal variance in ambient air pollution has recently been linked to exacerbation and mortality. We sought to examine the seasonal pattern of hospitalizations in Germany, use of mechanical ventilation, and in-hospital mortality on a year-by-year basis to identify their overall trend and to characterize seasonal patterns. Methods: The national in-patient database of the federal statistical office of Germany was searched for cases of interstitial lung disease. Results: A total of 130,366 hospitalizations for ILD occurred from 2005 to 2015. Time series data were examined for seasonality using X-11 statistics. The incidence of hospitalizations, mechanical ventilation, and in-hospital mortality show clear seasonal peaks in the cold season. The observed seasonality cannot be attributed to the variance of
\end{abstract}

karger@karger.com www.karger.com/res

Karger

GOPEN ACCESS
(C) 2021 The Author(s)

Published by S. Karger AG, Basel

This article is licensed under the Creative Commons Attribution 4.0 International License (CC BY) (http://www.karger.com/Services/ OpenAccessLicense). Usage, derivative works and distribution are permitted provided that proper credit is given to the author and the original publisher. selected comorbidities. Also, there is a significant overall upward trend regarding hospitalization counts, especially in the use of non-invasive ventilation. Conclusion: Time series analysis of in-hospital data shows an ILD-related rise of hospitalizations, in-hospital mortality, and non-invasive ventilation. This emphasizes a growing importance of interstitial lung diseases for health-care systems. Strong seasonality is seen in these variables. Data therefore support previous studies of ILD exacerbation. More research on infectious causes and environmental factors is warranted.

(c) 2021 The Author(s)

Published by S. Karger AG, Basel

\section{Introduction}

Interstitial lung disease (ILD) is a term comprising numerous chronic lung diseases which primarily involve the lung parenchyma [1]. Among these are non-infectious inflammatory (e.g., sarcoidosis and connective tissue disease) and non-inflammatory entities (e.g. idiopathic pulmonary fibrosis) [2]. All ILDs bear, to a different extent, the risk of permanent tissue scarring with the end-result of pulmonary fibrosis $[2,3]$. Shortness of breath, poor physiologic performance, and premature mortality are the con- 
sequences [1, 3-9]. ILDs are increasingly diagnosed in the recent years. Therefore, their incidence and prevalence are on the rise $[10,11]$. This may have an impact on hospitalization counts and thereby be of importance to health-care utilization [4]. Prognoses and treatment options of certain ILDs vary substantially $[4,12]$. Yet, it is increasingly recognized that a so-called acute exacerbation of ILD is a potentially life-threatening worsening of disease, irrespective of the initial trigger or the underlying disease entity $[2,3,5$, $6,9,13-19]$. Environmental factors and airway infections are established triggers of exacerbations in other chronic lung diseases, such as asthma and chronic obstructive lung disease [20,21]. Since infectious agents are regarded one major cause of acute exacerbations in many ILDs, and respiratory infections exhibit a seasonal variation, it is reasonable to assume that a seasonal pattern of exacerbations can be anticipated [13, 14, 18-20, 22, 23]. Environmental factors, such as ambient air pollution, have recently been linked to acute exacerbations of certain ILDs and increased mortality [24-26]. Particulate matter (PM10, PM2.5), nitric dioxide $\left(\mathrm{NO}_{2}\right)$, and ozone $\left(\mathrm{O}_{3}\right)$ have been named as culprit pollutants, and the clear seasonal variation of these factors is well documented [24-26]. To date, review of death certificates from the USA suggests that mortality from pulmonary fibrosis is greatest in winter [23]. In this study, we want to prove whether seasonal triggers also contribute to the variation of hospitalizations throughout the year. We therefore analysed the entire inpatient sample of Europe's largest economy using the DRG database of the federal statistics office of Germany.

\section{Materials and Methods}

\section{Database}

As previously described, nationwide health insurance claims of the entire inpatient sample were obtained from the Federal Statistical Office of Germany (DeStatis) (Source: DOI:10.21242/23141. 2005.00.00.1.1.0 to 10.21242/23141.2015.00.00.1.1.0, own calculations) [27]. DeStatis holds data according to the international classification of diseases, version 10 (ICD-10) data (German modification of the diagnosis related groups, G-DRG) $[28,29]$. Data were aggregated and analysed using SAS 9.4 (SAS Institute, Cary, USA).

\section{Case Selection}

The G-DRG classification of diseases parallels the WHO-ICD 10 definitions. The G-DRG database was searched for ICD code J84.1 comprising cases of interstitial lung disease and pulmonary fibrosis. Importantly, the definition includes IPF, but it is not exclusive (i.e., Hamman-Rich syndrome). Pulmonary fibrosis due to inhalation of chemicals, gases, fumes, or vapours or following radiation are excluded by definition. We further tried to estimate the specificity of the diagnosis by evaluating the prevalence of other conditions associated with pulmonary fibrosis. These include pneumoconiosis (J60-J65), hypersensitivity pneumonitis (HP) (J66-J67), rheumatoid arthritis (M06), and systemic connective tissue disorders (M30-36). In 11,002 cases (8.4\%), either of these conditions occurred as a co-diagnosis. For the purpose of comparison and control, cases of lung cancer (ICD code C34.x) were searched and analysed accordingly. Patient characteristics regarding age and gender distribution, use of non-invasive and mechanical ventilation, and mortality were extracted. To evaluate different severity levels of the primary outcome of hospitalizations, we defined firstly prolonged duration ( $>5$ days) and/or fatal cases, secondly cases with mechanical ventilation, and thirdly fatal cases.

\section{Statistical Analysis}

Serial quarterly hospitalization counts from 2005 to 2015 were analysed for seasonal variance using the X11 procedure as provided by SAS 9.4 [30]. PROC X11 is an adaptation of the US Bureau of the Census X-11 Seasonal Adjustment program and seasonally adjusts monthly or quarterly time series [30]. The output data sets contain the adjusted time series and statistical measures of seasonality [30]. Seasonal data (i.e., winter $=$ January - March; spring = April - June; summer = July - September; and autumn $=$ October - December) were analysed for the presence of seasonality. Upon comparison of high- and low-incidence seasons, the variances in quarter lengths were considered, and normalization to 90-day quarters (Q90) was performed. Generalized linear models (PROC GENMOD, using a Poisson regression) were used to confirm the significance of peak versus minimum seasons. Temporal trends were analysed using generalized linear models as provided by PROC GLM. Descriptive data regarding the use of non-invasive and/or mechanical ventilation, age and gender composition of the cohort are given as absolute and relative numbers and as mean and median \pm standard deviation (SD), where applicable. Unless stated otherwise, the $t$ test was used to compare continuous patient variables. Odds ratios including confidence intervals and $p$ values were calculated, as previously described $[31,32]$.

\section{Results}

\section{Hospitalizations and Patient Characteristics}

A total of 130,366 hospitalizations for ILD were found from 2005 to 2015. According to these, the hospitalization rate for interstitial lung disease is 14.75 per 100,000 per year. Female and male patients do not differ regarding their age (mean age 67.64 and 68.18 years). Yet, descriptive statistics suggest that male patients are more frequently hospitalized for ILDs than female patients (hospitalization rates: 17.67 vs. 11.97 , OR 1.48) (Table 1). Hospitalization rates increase with age and are highest among patients aged 71-80 (55.96; OR 5.46) years (Table 1). The lowest hospitalization rate (2.25) is found in patients $0-50$ years (OR 0.066) (Table 1). The hospitalizations show an average annual increase of $3.81 \%$ per year. A total of 932,144 hospitalizations for lung cancer were recorded from 2005 to 2015. 
Table 1. Hospitalizations and fatal cases

\begin{tabular}{|c|c|c|c|c|c|c|c|c|c|c|c|c|}
\hline \multicolumn{13}{|c|}{ Age group, years } \\
\hline $0-50$ & 12,002 & 2.25 & 0.066 & 0.065 & 0.068 & $<0.0001$ & 298 & 2.48 & 0.020 & 0.018 & 0.022 & $<0.0001$ \\
\hline $51-60$ & 17,911 & 14.20 & 0.956 & 0.941 & 0.971 & $<0.0001$ & 770 & 4.30 & 0.490 & 0.454 & 0.528 & $<0.0001$ \\
\hline$>80$ & 17,630 & 42.69 & 3.200 & 3.150 & 3.252 & $<0.0001$ & 2,304 & 13.07 & 5.945 & 5.659 & 6.246 & $<0.0001$ \\
\hline \multicolumn{13}{|l|}{ Gender } \\
\hline Female & 54,102 & 11.97 & 0.677 & 0.669 & 0,684 & $<0.0001$ & 3,642 & 6.73 & 0.529 & 0.507 & 0.552 & $<0.0001$ \\
\hline Male & 76,264 & 17.67 & 1.478 & 1.461 & 1.494 & $<0.0001$ & 6,571 & 8.62 & 1.890 & 1.813 & 1.971 & $<0.0001$ \\
\hline All & 130,366 & 14.75 & & & & & 10,213 & 7.83 & & & & \\
\hline
\end{tabular}

Numbers are given as absolute counts $(N)$ and as rate per 100,000 by age group, gender, and in total. ORs of subgroups are in comparison to the total cohort of hospitalized and fatal cases, respectively. OR, odds ratio.

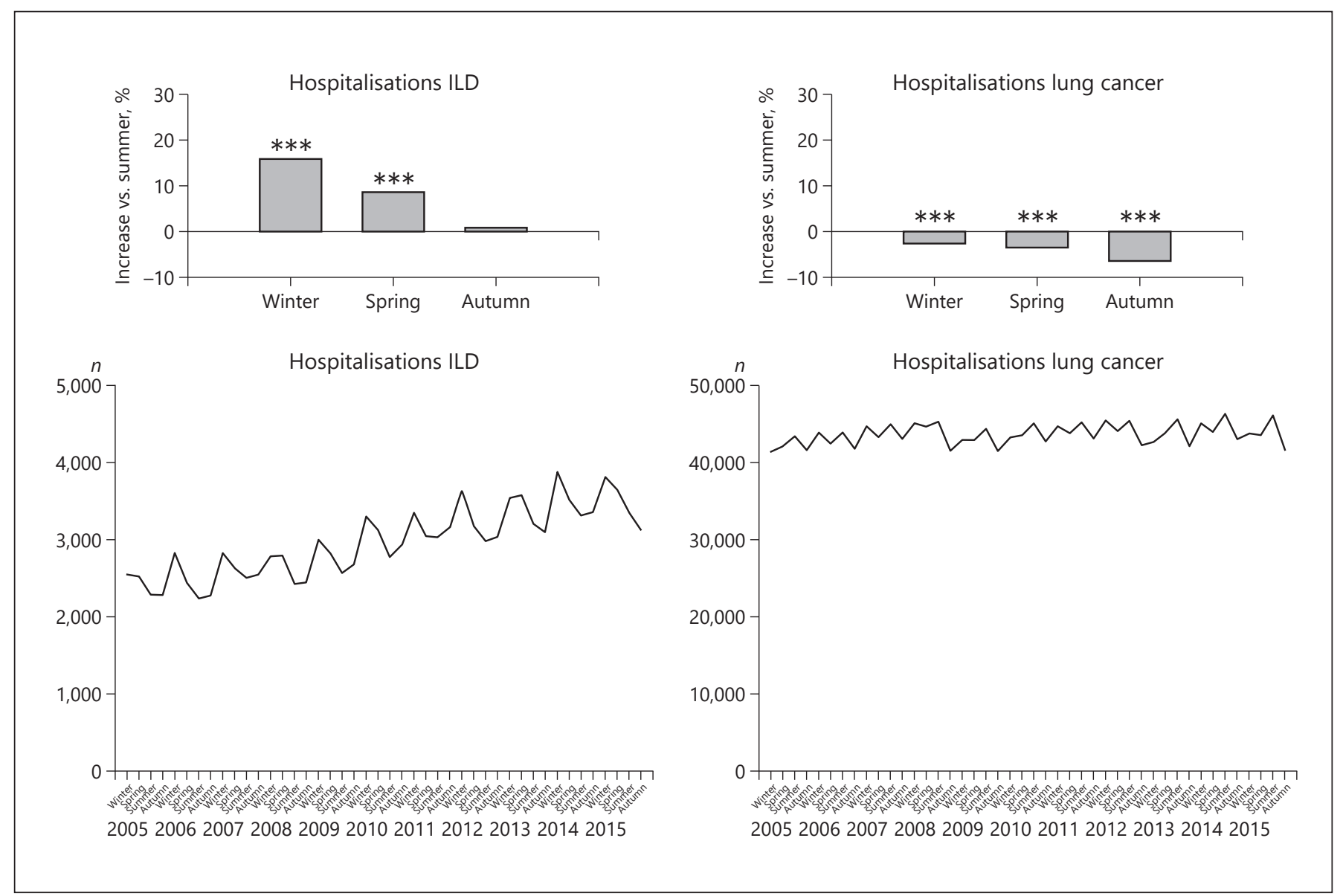

Fig. 1. Seasonality of hospitalizations for interstitial lung disease and lung cancer. Upper panels highlight seasonal differences as percent increase versus summer. Lower panels show seasonal variance throughout the study period $(2005-2015)(* * * p<0.001)$. 


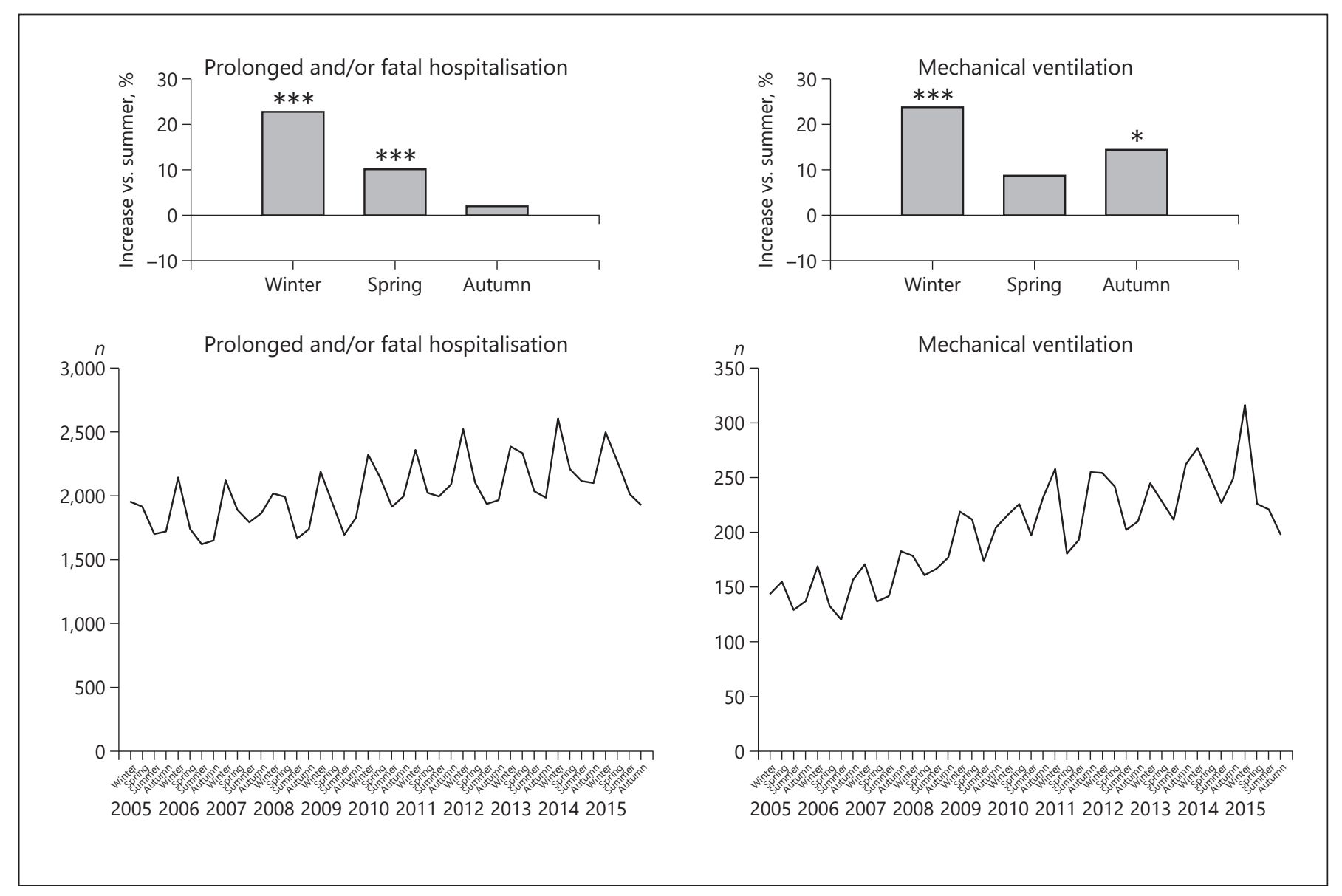

Fig. 2. Seasonality of in-hospital prolonged and/or fatal cases and cases of mechanical ventilation in patients hospitalized for ILD. Upper panels highlight seasonal differences as percent increase summer. Lower panels show seasonal variance throughout the study period $(2005-2015)\left({ }^{*} p<0.05,{ }^{* * *} p<0.001\right)$.

\section{In-Hospital Mortality}

ILD-related in-hospital mortality is high (7.83\%) and can be even higher in advanced age (i.e., up to $13.07 \%$ in patients $>80$ year (Table 1 ). The mortality of younger patients $(<50$ year) is lower but still considerable $(2.48 \%)$ (Table 1). As compared to female patients, male patients have a higher mortality rate (OR 1.89, $p<0.0001)$ (Table 1).

\section{Seasonal Variation of Hospitalizations}

Hospitalizations for ILD exhibit an obvious seasonal pattern, with highest adjusted counts in winter $(3,227$ in winter vs. 2,787 in summer). Likewise, hospitalizations for lung cancer follow a seasonal pattern, with highest average adjusted hospitalization counts in winter $(21,882$ in winter vs. 19,502 in autumn). In both cases, X-11 statistics can confirm the presence of seasonality (Fig. 1). Yet, important differences are noted. In the case of ILD, the season with the lowest average counts is summer, while autumn shows the lowest hospitalization count for lung cancer hospitalizations. Also, the magnitude of seasonality is greatly higher in ILD patients than in lung cancer patients (ILD, winter vs. summer: $15.8 \%, p<0.0001$; lung cancer, winter vs. summer: $-2.6 \%, p<0.0001$ ) (Fig. 1). We hypothesized that cases with a more severe course (prolonged duration, cases with mechanical ventilation and fatal cases) are related to an increasing degree of seasonality. Likewise, the increase was more pronounced in cases with prolonged hospitalization ( $>5$ days and/or fatal) in comparison to all cases $(22.78 \%$ winter vs. summer $p<0.0001)$ (Fig. 2). The relation of winter versus summer in cases with the use of mechanical ventilation was slightly higher $(23.62 \%$ winter vs. summer $p<0.001)$ (Fig. 2) and highest in fatal cases (32.77\% winter vs. summer $p<0.0001$ ) (Fig. 3). In contrast, lung cancer mortality was not related to season (1.06\% winter vs. summer $p=0.0927$ ) (Fig. 3). 


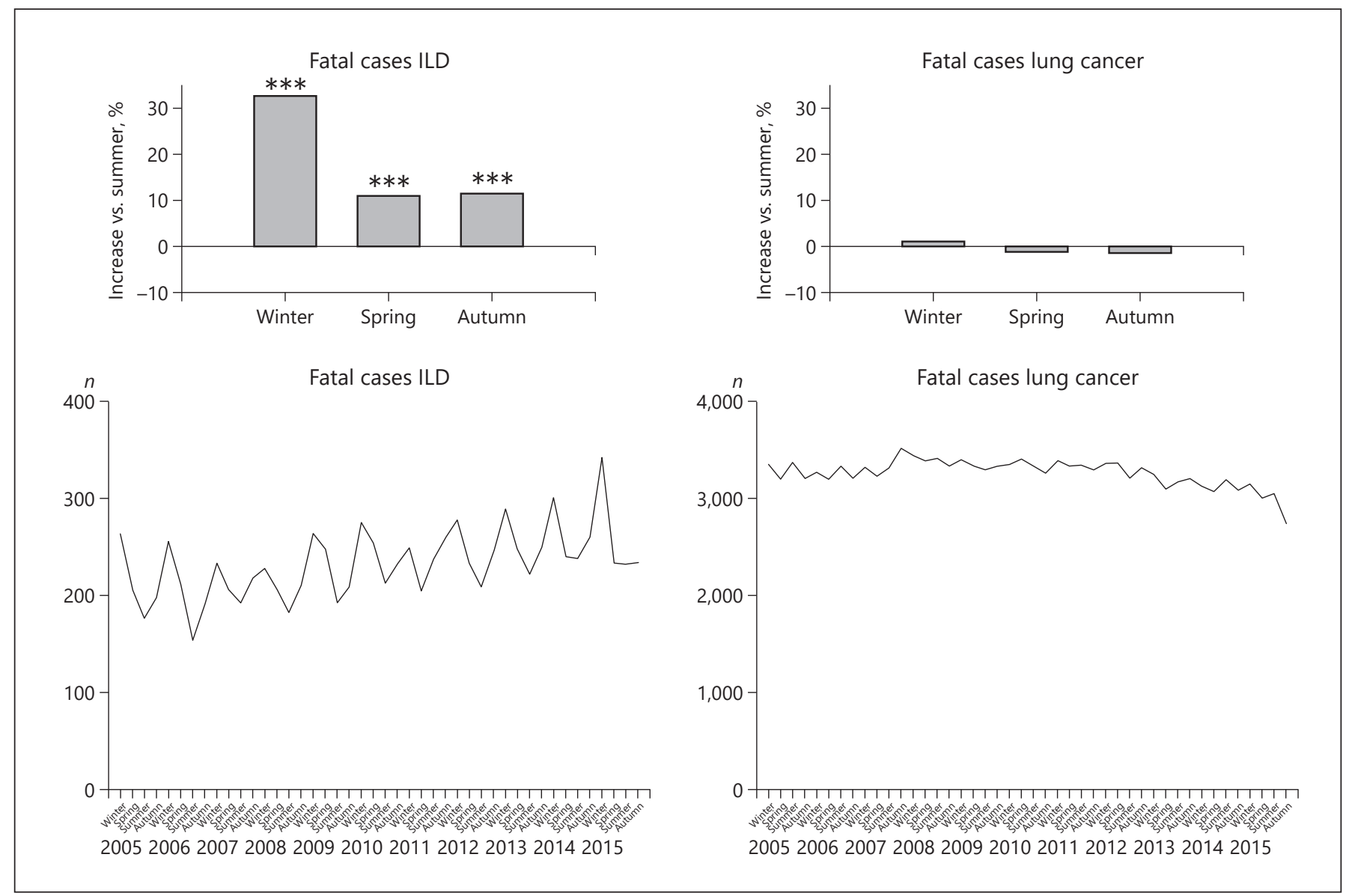

Fig. 3. Seasonality of fatal cases among patients hospitalized for ILD and lung cancer. Upper panels highlight seasonal differences as percent increase versus summer. Lower panels show seasonal variance throughout the study period $(2005-2015)(* * * p<0.001)$.

Table 2. Cases of mechanical ventilation and non-invasive ventilation

\begin{tabular}{|c|c|c|c|c|c|c|c|c|c|c|c|c|}
\hline & \multicolumn{6}{|c|}{ Mechanical ventilation } & \multicolumn{6}{|l|}{ NIV } \\
\hline $0-50$ & 596 & 4.97 & 1.358 & 1.244 & 1.482 & $<0.0001$ & 505 & 4.21 & 0.869 & 0.792 & 0.954 & 0.002 \\
\hline $51-60$ & 905 & 5.05 & 1.415 & 1.314 & 1.523 & $<0.0001$ & 865 & 4.83 & 1.019 & 0.947 & 1.097 & 0.305 \\
\hline $61-70$ & 1,435 & 4.15 & 1.128 & 1.059 & 1.200 & $<0.0001$ & 1,738 & 5.03 & 1.085 & 1.025 & 1.149 & 0.002 \\
\hline \multicolumn{13}{|l|}{ Gender } \\
\hline Female & 1,855 & 3.43 & 0.830 & 0.783 & 0.880 & $<0.0001$ & 2,336 & 4.32 & 0.846 & 0.803 & 0.892 & $<0.0001$ \\
\hline Male & 3,127 & 4.10 & 1.204 & 1.136 & 1.277 & $<0.0001$ & 3,862 & 5.06 & 1.182 & 1.122 & 1.246 & $<0.0001$ \\
\hline All & 4,982 & 3.82 & & & & & 6,198 & 4.75 & & & & \\
\hline
\end{tabular}

Numbers are given as absolute counts $(N)$ and rate per hospitalized cases by age groups, by gender, and in total. Odds ratios are to compare individual subgroups to all cases of mechanical ventilation and non-invasive ventilation, respectively. 
Table 3. Absolute count and rate of comorbidities and comorbid conditions among patients with interstitial lung disease across seasons

\begin{tabular}{|c|c|c|c|c|c|c|c|c|}
\hline & \multicolumn{2}{|l|}{ winter } & \multicolumn{2}{|l|}{ spring } & \multicolumn{2}{|c|}{ summer } & \multicolumn{2}{|c|}{ autumn } \\
\hline \multicolumn{9}{|l|}{ Comorbidity } \\
\hline COPD & 3,224 & $(12.83)$ & 2,813 & $(12.48)$ & 2,620 & $(12.80)$ & 2,630 & $(12.61)$ \\
\hline $\mathrm{HP}$ & 417 & (1.66) & 385 & (1.71) & 329 & $(1.61)$ & 355 & (1.70) \\
\hline RA & 648 & $(2.58)$ & 651 & $(2.89)$ & 616 & $(3.01)$ & 578 & $(2.77)$ \\
\hline Systemic disease & 678 & $(2.70)$ & 530 & $(2.35)$ & 548 & $(2.68)$ & 583 & $(2.79)$ \\
\hline CAD & 8,459 & (33.66) & 7,590 & (33.68) & 6,906 & (33.74) & 7,233 & (34.67) \\
\hline $\mathrm{Ml}$ & 179 & $(0.71)$ & 157 & $(0.70)$ & 161 & $(0.79)$ & 143 & $(0.69)$ \\
\hline $\mathrm{PE}$ & 305 & $(1.21)$ & 233 & $(1.03)$ & 213 & (1.04) & 237 & (1.14) \\
\hline \multicolumn{9}{|c|}{ Patient residential area } \\
\hline Urban & 10,586 & $(45.85)$ & 9,280 & $(45.16)$ & 8,571 & $(45.88)$ & 8,949 & (46.56) \\
\hline Suburban & 8,021 & $(34.74)$ & 7,222 & (35.15) & 6,492 & (34.75) & 6,524 & (33.94) \\
\hline Rural & 4,483 & $(19.42)$ & 4,047 & (19.69) & 3,620 & (19.38) & 3,747 & (19.50) \\
\hline
\end{tabular}

Absolute counts $(N)$ and rates (\%; i.e., cases with respective comorbidities as percentage of all cases). Information on patient residential area, according to the definition of the Federal Institute for Research on Building, Urban Affairs, and Spatial Development, was available for $91.6 \%$ of all patient datasets. HP, hypersensitivity pneumonitis; RA, rheumatoid arthritis; CAD, coronary artery disease; MI, myocardial infarction; PE, pulmonary embolism; COPD, chronic obstructive lung disease.

\section{Mechanical and Non-Invasive Ventilation}

Descriptive statistics show that the use of mechanical and non-invasive ventilation is higher in male patients than in female patients (ORs 1.204 and 1.182, both $p<0.0001$ ) (Table 2). Differences in the age of patients needing mechanical ventilation are seen (Table 2). Mechanical ventilation is more likely in younger individuals than in older patients. Very old patients ( $>80$ years) are least likely to receive mechanical ventilation (Table 2). Non-invasive ventilation is preferably used in all age groups, except young patients $(<50$ years) and old patients ( $>80$ years) (Table 2$)$. As in mechanically ventilated cases in total, invasive and NIV show a comparable seasonal pattern $(21.2 \%$ and $16.3 \%$, respectively, winter vs. summer $p<0.001$, data not shown).

\section{Impact of Comorbidities on Seasonality of Fibrosis}

Table 3 gives a summary of the absolute and relative frequencies of important comorbidities and comorbid conditions to be found in ILD patients. High-prevalence co-diagnoses are coronary artery disease (33.9\%), chronic obstructive lung disease (12.6\%) and pneumonia $(10.2 \%)$. However, these do not explain the overall sea- sonality of hospitalizations as the odds ratio for winter hospitalizations are 1.02, 0.99, and 1.10. As expected, influenza as a secondary diagnosis, shows a clear winter peak. Yet the prevalence of this ICD code as a co-diagnosis is not high in patients with ILD (maximum $0.22 \%$ in winter). Likewise, pulmonary embolism shows a winter peak, but also has a low prevalence (maximum $1.21 \%$, OR 1.17). Thus, influenza and pulmonary embolism do not explain the aforementioned seasonality in ILD. Other codiagnoses (HP, pneumoconiosis, systemic disease, rheumatoid disease) do not reveal high prevalence and/or winter peaks.

\section{Discussion}

We hereby demonstrate for the first time seasonality of hospital admissions, use of ventilation, and in-hospital mortality in the context of ILD on a population-based level. This phenomenon has been described for overall mortality in 2009 by Olson et al. as they showed seasonal variation of mortality from ILD in the USA [23]. Their 
study spanned from 1992 to 2003 and identified 170,984 decedents with ILD [23]. They were able to provide evidence that mortality is greatest during the colder seasons (winter $>$ spring $>$ autumn $>$ summer) [23]. The investigators attributed the higher winter death toll at least in part to influenza epidemics, which recur in a yearly manner (December through March), and ensuing superimposed bacterial infections [23, 27]. Yet, when excluding patient records with pneumonia, seasonal variation was consistently shown [23]. Clinically recognized airway infections may thus not be the only underlying cause leading to the death of PF patients [33]. This is in line with our own data, demonstrating that hospital admissions for interstitial lung disease and pulmonary fibrosis, use of mechanical ventilation, and in-hospital mortality follow a remarkably similar distinct pattern. This observation suggests a seasonal of variation not only mortality but also morbidity. Olson et al. [23] and Nakaji et al. [34] only found trivial increases (2.7 and $4.0 \%$ ) of cancer mortality in winter as compared with summer. This is in accordance with our study as we found variation of mortality at the same magnitude.

It is meanwhile widely recognized that there are infectious and (partly unknown) non-infectious triggers leading to the acute exacerbation of interstitial lung disease $[3,5,6,14,22]$. Ambient air pollutants $\left(\mathrm{O}_{3}\right.$ and $\left.\mathrm{PM}\right)$ have recently been described to be closely correlated to exacerbations of IPF [24-26]. While $\mathrm{O}_{3}$ concentrations are usually higher in summer, higher particulate matter load is generally associated with winter weather [24-26]. Individual biological and behavioural aspects vary substantially between winter and summer [33]. While temperature as such has been linked to excess mortality, lack of daylight alters vitamin D levels and immunological host constitution via, for example, hormonal changes $[33,35]$. Cold temperatures are a motive for people to gather indoors, which readily facilitates pathogen spread from person to person [36]. These facts may contribute to the seasonal variation of ILD hospitalizations [36]. A trend towards more ILD-related hospitalizations and more fatal cases can be derived from our data set. GLM analyses of the above 11-year period conclusively show that an upward trend is superimposed on the seasonal pattern. As for US mortality data, a strong trend has been identified from 1992 to 2003, with an average age- and sex-adjusted increase of $28.3 \%$ in men and $41.3 \%$ in women [10,23]. ILDs are still considered rare orphan diseases, many of which are difficult to consider for randomized trials of pharmacological agents [1]. These findings are sign of a growing burden of and greater awareness for interstitial lung diseases and related mortality, which exceeds that of several malignancies $[10,11]$. A rise of hospitalization counts would directly impact health-care expenditure. A number of comorbidities in patients with certain interstitial lung diseases have been identified in the past, and their impact on morbidity and mortality has been characterized [37]. In ILD, comorbidities have the potential to impair quality of life and to reduce life expectancy [37]. It is reasonable to assume that co-morbidities and co-diagnoses may be driving factors for hospital admissions and thereby be one important underlying cause for the observed seasonality. Yet, the data, as compiled in Table 3, do not point in this direction. The prevalence of diagnoses with high seasonality and/or winter predominance is considerably low in patients with ILD. On the other hand, high-prevalence diagnoses do not show a relevant variance over the course of the seasons. Overall, these factors do not conclusively explain the observed seasonality of fibrotic ILD. There are certain limitations to this study. One important limitation arises from the fact that retrospective data are extracted from a database which has the primary purpose to facilitate health-care insurance processing [27-29]. We cannot directly ensure coding quality as such. Yet, coding accuracy is monitored by the professional medical service to the statutory health insurance, which reviews about $10 \%$ of all insurance claims $[28,29]$. Another limitation comes from the DRG system itself, which does not allow for a detailed resolution of ILDs regarding their aetiology since the ICD code J84.1 comprises diverse entities most prominently but not exclusively IPF. This phenomenon is consistently found in studies of ILD hospitalizations on a population-based level $[11,38]$. We therefore tried to classify cases with other specific causes of pulmonary fibrosis such as pneumoconiosis, HP, rheumatoid arthritis, and systemic connective tissue disorders. These were identified in a minority $(8.3 \%)$ of all hospitalizations. This study does also not provide a direct insight into the underlying mechanisms that lead to hospitalization and mortality, although, considering the recent research in this field, it is very reasonable to assume that acute exacerbations, regardless of the trigger, account for much of the seasonal variation seen in ILD hospitalizations [6, 18, 22-25]. However, pneumonia is only moderately more frequent in winter than during the rest of the year, and influenza with a strong seasonality is only present in a minuscule portion of overall cases $(0.22 \%$ in winter). Influenza exhibits a strong seasonal distribution and marked winter peaks in our hemisphere $[27,39]$. Other authors have suggested influenza infection as one underlying cause of seasonality in 
ILD and other chronic lung disease [16, 23]. While a direct explanation for this cannot be derived from our dataset, it is reasonable to assume that influenza vaccination is applied to ILD patients on a regular basis since these patients are seen by health-care providers on a frequent basis, and flu vaccination of patients with lung disease is officially recommended by the German Standing Committee on Vaccination (STIKO) [40].

\section{Conclusion}

Taken together, our data indicate that ILD-related hospitalizations show a strong seasonal variation, which is more pronounced in cases with prolonged hospitalization, mechanical ventilation, and fatal outcome. This is not common with other less seasonal lung diseases, such as lung cancer. Frequent comorbidities do not contribute to the observed seasonality. There is reason to believe that these findings are related to the activity of the disease and complications such as acute exacerbation of ILD.

\section{Acknowledgments}

We thank the staff of the German federal statistics office (DeStatis) for the kind provision of data.

\section{Statement of Ethics}

De-identified and aggregated data are provided in compliance with the DeStatis anonymization policy and in full accordance to EU data protection laws. A requirement for further institutional review therefore does not apply upon data release by DeStatis.

\section{Conflict of Interest Statement}

D.B. declares no conflict of interest exists. F.G. declares no conflict of interest exists. W.S. received consulting fees from Actelion, Abivax, United Therapeutics, Vectura, Medspray, Bayer AG, and Liquidia. A.G. received consulting fees from Roche, BoehringerIngelheim, LungTherapeutics, and Astra Zeneca. B.L. received consulting fees from Novartis, Roche AG, Novartis AG, Chugai Pharma, Menarini Berlin-Chemie, MSD, Boehringer Ingelheim, Pfizer, and BMS. No specific funding was received for this study.

\section{Funding Sources}

No specific funding was obtained to conduct this study.

\section{Author Contributions}

D.B. and B.L. took care of conceptualization, data curation, data acquisition, data analysis and interpretation, visualization, and manuscript writing. A.G., F.G., and W.S. supervised the project, provided resources, and took part in data analysis. All authors contributed to the study and have been involved in drafting or revising the manuscript for important intellectual content. All authors read and approved the final manuscript. B.L. is the guarantor of the manuscript.

\section{Data Availability Statement}

Data can be obtained from the German Federal Statistical Office (DeStatis). All relevant aggregated data, as used to create this paper, are either contained in the paper or are available on reasonable request.

\section{References}

1 Cottin V, Wollin L, Fischer A, Quaresma M, Stowasser S, Harari S. Fibrosing interstitial lung diseases: knowns and unknowns. Eur Respir Rev. 2019;28:180100.

2 Enomoto N, Oyama Y, Enomoto Y, Yasui H, Karayama M, Kono M, et al. Differences in clinical features of acute exacerbation between connective tissue disease-associated interstitial pneumonia and idiopathic pulmonary fibrosis. Chron Respir Dis. 2019;16: 1479972318809476.

3 Leuschner G, Behr J. Acute exacerbation in interstitial lung disease. Front Med. 2017;4: 176.

4 Disayabutr S, Calfee CS, Collard HR, Wolters PJ. Interstitial lung diseases in the hospitalized patient. BMC Med. 2015;13:245.
5 Miyamoto A, Sharma A, Nishino M, MinoKenudson M, Matsubara O, Mark EJ. Expanded acceptance of acute exacerbation of nonspecific interstitial pneumonia, including 7 additional cases with detailed clinical pathologic correlation. Pathol Int. 2018;68:401-8.

6 Spagnolo P, Wuyts W. Acute exacerbations of interstitial lung disease: lessons from idiopathic pulmonary fibrosis. Curr Opin Pulm Med. 2017;23:411-7.

7 Doubková M, Švancara J, Svoboda M, Šterclová M, Bartoš V, Plačková M, et al. EMPIRE registry, Czech part: impact of demographics, pulmonary function and HRCT on survival and clinical course in idiopathic pulmonary fibrosis. Clin Respir J. 2018;12:152635.
8 Kang HS, Cho KW, Kwon SS, Kim YH. Prognostic significance of Glasgow prognostic score in patients with acute exacerbation of idiopathic pulmonary fibrosis. Respirology. 2018;23:206-12.

9 Paterniti MO, Bi Y, Rekić D, Wang Y, KarimiShah BA, Chowdhury BA. Acute exacerbation and decline in forced vital capacity are associated with increased mortality in idiopathic pulmonary fibrosis. Ann Am Thorac Soc. 2017;14:1395-402.

10 Olson AL, Swigris JJ, Lezotte DC, Norris JM, Wilson CG, Brown KK. Mortality from pulmonary fibrosis increased in the United States from 1992 to 2003. Am J Respir Crit Care Med. 2007;176:277-84. 
11 Navaratnam V, Fleming KM, West J, Smith CJ, Jenkins RG, Fogarty A, et al. The rising incidence of idiopathic pulmonary fibrosis in the U.K. Thorax. 2011;66:462-7.

12 Spagnolo P, Tzouvelekis A, Bonella F. The management of patients with idiopathic pulmonary fibrosis. Front Med. 2018;5:148.

13 Atsumi K, Saito Y, Kuse N, Kobayashi K, Tanaka T, Kashiwada T, et al. Prognostic factors in the acute exacerbation of idiopathic pulmonary fibrosis: a retrospective singlecenter study. Intern Med. 2018;57:655-61.

14 Azadeh N, Limper AH, Carmona EM, Ryu $\mathrm{JH}$. The role of infection in interstitial lung diseases: a review. Chest. 2017;152:842-52.

15 Kärkkäinen M, Nurmi H, Kettunen HP, Selander T, Purokivi M, Kaarteenaho R. Underlying and immediate causes of death in patients with idiopathic pulmonary fibrosis. BMC Pulm Med. 2018;18:69.

16 Kondoh Y, Cottin V, Brown KK. Recent lessons learned in the management of acute exacerbation of idiopathic pulmonary fibrosis. Eur Respir Rev. 2017;26:170050.

17 Marchioni A, Tonelli R, Ball L, Fantini R, Castaniere I, Cerri S, et al. Acute exacerbation of idiopathic pulmonary fibrosis: lessons learned from acute respiratory distress syndrome? Crit Care. 2018;22:80.

18 Qiu M, Chen Y, Ye Q. Risk factors for acute exacerbation of idiopathic pulmonary fibrosis: a systematic review and meta-analysis. Clin Respir J. 2018;12:1084-92.

19 Yamazoe M, Tomioka H. Acute exacerbation of idiopathic pulmonary fibrosis: a 10 -year single-centre retrospective study. BMJ Open Respir Res. 2018;5:e000342.

20 Donaldson GC, Wedzicha JA. COPD exacerbations 1: epidemiology. Thorax. 2006;61:164-8.

21 McCormack MC, Paulin LM, Gummerson CE, Peng RD, Diette GB, Hansel NN. Colder temperature is associated with increased COPD morbidity. Eur Respir J. 2017;49: 1601501.
22 Collard HR, Ryerson CJ, Corte TJ, Jenkins G, Kondoh Y, Lederer DJ, et al. Acute exacerbation of idiopathic pulmonary fibrosis. An International Working Group report. Am J Respir Crit Care Med. 2016;194:265-75.

23 Olson AL, Swigris JJ, Raghu G, Brown KK. Seasonal variation: mortality from pulmonary fibrosis is greatest in the winter. Chest. 2009; 136:16-22.

24 Johannson KA, Vittinghoff E, Lee K, Balmes JR, Ji W, Kaplan GG, et al. Acute exacerbation of idiopathic pulmonary fibrosis associated with air pollution exposure. Eur Respir J. 2014;43:1124-31.

25 Jones MG, Richeldi L. Air pollution and acute exacerbations of idiopathic pulmonary fibrosis: back to miasma? Eur Respir J. 2014;43: 956-9.

26 Sesé L, Nunes H, Cottin V, Sanyal S, Didier M, Carton Z, et al. Role of atmospheric pollution on the natural history of idiopathic pulmonary fibrosis. Thorax. 2018;73:145-50.

27 von der Beck W, Seeger W, Herold S, Günther A, Löh B. Characteristics and outcomes of a cohort hospitalized for pandemic and seasonal influenza in Germany based on nationwide inpatient data. PLoS One. 2017;12:e0180920.

28 Gaertner T, Lehr F, Blum B, van Essen J. Einheitlichkeit der richtlinienkonformen Begutachtung durch den Medizinischen Dienst der Krankenversicherung bei der Prüfung der Kodierung im G-DRG-System. Gesundheitswesen. 2015;77(08/09):559-64.

29 Becker A, Pfeuffer B, Beck U. MDK-Aufwandspauschale: Fakten versus Phantasie. krankenhaus umschau. 2007;76:508-12.

30 SAS Institute Inc. SAS/ETS 14.3 user's guide: the X11 procedure. Cary, NC: SAS Institute Inc; 2017.
31 Altman DG. Practical statistics for medical research. 1st ed. London: Chapman and Hall; 1991.

32 Sheskin DJ. Handbook of parametric and nonparametric statistical procedures. 3 rd ed. Baton Rouge: CRC Press; 2004

33 The Eurowinter Group. Cold exposure and winter mortality from ischaemic heart disease, cerebrovascular disease, respiratory disease, and all causes in warm and cold regions of Europe. Lancet 1997;349:1341-6.

34 Nakaji S, Parodi S, Fontana V, Umeda T, Suzuki K, Sakamoto J, et al. Seasonal changes in mortality rates from main causes of death in Japan (1970-1999). Eur J Epidemiol. 2004;19: $905-13$

35 Jolliffe DA, Greenberg L, Hooper RL, Mathyssen C, Rafiq R, de Jongh RT, et al. Vitamin D to prevent exacerbations of COPD: systematic review and meta-analysis of individual participant data from randomised controlled trials. Thorax. 2019;74:337-45.

36 Wood R, Morrow C, Ginsberg S, Piccoli E, Kalil D, Sassi A, et al. Quantification of shared air: a social and environmental determinant of airborne disease transmission. PLoS O. 2014;9:e106622.

37 Margaritopoulos GA, Antoniou KM, Wells AU. Comorbidities in interstitial lung diseases. Eur Respir Rev. 2017;26:160027.

38 Gibson GJ, Loddenkemper R, Sibille Y, Lundback B. The European lung white book: respiratory health and disease in Europe. 2nd ed. Sheffield: European Respiratory Society; 2013.

39 Pebody RG, Green HK, Warburton F, Sinnathamby M, Ellis J, Mølbak K, et al. Significant spike in excess mortality in England in winter 2014/15: influenza the likely culprit. Epidemiol Infect. 2018;146:1106-13.

40 Robert Koch-Institut: Epidemiologisches Bulletin des Robert Koch-Institus Ausgabe 34/2017. 